\title{
Article
}

\section{Impact of Extraction Process in Non-Compliant 'Bravo de Esmolfe' Apples towards the Development of Natural Antioxidant Extracts}

\author{
Ana A. Vilas-Boas ${ }^{1}\left(\mathbb{D}\right.$, Ana Oliveira ${ }^{1, *(\mathbb{D})}$, Tânia B. Ribeiro ${ }^{1}\left(\mathbb{D}\right.$, Sónia Ribeiro ${ }^{2}$, Catarina Nunes ${ }^{2}$, \\ Ricardo Gómez-García ${ }^{1}{ }^{\mathbb{D}}$, João Nunes ${ }^{2}$ and Manuela Pintado ${ }^{1}$ \\ 1 Centro de Biotecnologia e Química Fina, Laboratório Associado, Escola Superior de Biotecnologia, \\ Universidade Católica Portuguesa, CBQF, Rua Diogo Botelho 1327, 4169-005 Porto, Portugal; \\ avboas@porto.ucp.pt (A.A.V.-B.); tribeiro@porto.ucp.pt (T.B.R.); rgarcia@porto.ucp.pt (R.G.-G.); \\ mpintado@porto.ucp.pt (M.P.) \\ 2 Centre Bio R\&D Unit, Association BLC3-Technology and Innovation Campus, Senhora da Conceição 2, \\ Oliveira do Hospital, 3045-155 Lagares, Portugal; sonia.ribeiro@blc3.pt (S.R.); catarina.nunes@blc3.pt (C.N.); \\ joao.nunes@blc3.pt (J.N.) \\ * Correspondence: asoliveira@porto.ucp.pt
}

Citation: Vilas-Boas, A.A.;

Oliveira, A.; Ribeiro, T.B.; Ribeiro, S.; Nunes, C.; Gómez-García, R.; Nunes, J.; Pintado, M. Impact of Extraction Process in Non-Compliant 'Bravo de Esmolfe' Apples towards the Development of Natural Antioxidant Extracts. Appl. Sci. 2021, 11, 5916. https://doi.org/10.3390/app11135916

Academic Editors: Marcos

Fallanza Torices and

Lucía Gómez-Coma

Received: 18 May 2021

Accepted: 21 June 2021

Published: 25 June 2021

Publisher's Note: MDPI stays neutra with regard to jurisdictional claims in published maps and institutional affiliations.

Copyright: (c) 2021 by the authors. Licensee MDPI, Basel, Switzerland. This article is an open access article distributed under the terms and conditions of the Creative Commons Attribution (CC BY) license (https:// creativecommons.org/licenses/by/ $4.0 /)$.
Abstract: The 'Bravo de Esmolfe' apple (BE) is rich in antioxidants and represents one of the most important traditional cultivars in Portugal. A large amount of non-compliant BE, with no market value, it is generated every year. Thus, an effort to find value-added solutions is of utmost importance. For the first time, green extraction (microwave-assisted-extraction (MAE) and ultrasound-assisted-extraction (UAE)) were compared against conventional extraction (with (CET) and without temperature (CE)) to select the most efficient process to produce a natural antioxidant extract from non-compliant BE. The results showed that MAE and CET are good methodologies for developing a BE antioxidant extract. However, MAE is more sustainable than CET, requiring less time to reach high temperatures. The MAE-extract showed great antioxidant activity $(14.80 \pm 0.70 \mathrm{mg}$ TE/g DE by ORAC, $3.92 \pm 0.25 \mathrm{mg} \mathrm{AAE} / \mathrm{g}$ DE by ABTS, and $5.11 \pm 0.13 \mathrm{mg}$ TE/g DE by DPPH). This extract revealed high amount of chlorogenic acid $(0.48 \pm 0.07 \mathrm{mg} / \mathrm{g} \mathrm{DE}),(-)$-epicatechin $(0.30 \pm 0.02 \mathrm{mg} / \mathrm{g} \mathrm{DE})$ and phloridzin $(0.13 \pm 0.01 \mathrm{mg} / \mathrm{g} \mathrm{DE})$. This study shows that non-compliant BE is a useful source of antioxidants, being a sustainable way for the recovery of value-added compounds from the rejected fruit in line with sustainable and circular bioeconomy principles.

Keywords: 'Bravo de Esmolfe' apple; food waste; polyphenols; antioxidant; sustainable extraction methods

\section{Introduction}

Apples are widely consumed globally [1], being one of the significant sources of antioxidants in the human diet [2]. Several works have reported the potent antioxidant activity of apple extracts that are mainly related to the presence of phenolic compounds, rather than from vitamin $C$ or vitamin E [1-3]. Among apple cultivars, traditional cultivars as the Portuguese variety 'Bravo de Esmolfe' (BE) revealed to be a much richer source of phenolics than exotic varieties consumed worldwide (e.g., Red Delicious, Golden Delicious, Fuji and Granny Smith) [1,2]. Nevertheless, the studies about the potential health-promoting properties of traditional apples, especially from the BE apple, have been limited [2-4]. The $\mathrm{BE}$ apple is known by its aroma/flavour properties, and consumers highly appreciate it. This apple was recognized as a product with Protected Designation of Origin (PDO), with great impact on the local and national economy [3,4]. Its production was restricted to a small inland region in northern Portugal ('Beiras'), not exceeding 200 tons per year. Still, commercial demand is now increasing due to its appealing sensory properties [1,3]. However, a substantial percentage of the small production of BE apple does not meet the quality 
standards regarding size or exhibit small defects, i.e., it was considered non-compliant fruit [5]. This non-compliant fruit was rejected or sold at lower prices for not being suitable for commercialization. However, its rich composition in terms of phytochemicals remain intact and could be explored. This will allow a high-value pathway for these non-profitable fruits, applying the circular economy concept in food supply chain (decreasing the food losses) and improve the economic sustainability of fruit production in the 'Beiras' region.

The appellative sensorial characteristics of BE apple are unquestionable and its texture [6], volatile profile [7] and sensory attributes have already been studied [1]. Nevertheless, recently, $\mathrm{BE}$ apple also revealed a rich composition in (+)-catechin, (-)-epicatechin, chlorogenic acid, phloridzin, phloretin and other phenolics such as procyanidin B1 and B2 [1-3]. The latter compounds belong to the class of phenolic compounds, which are bioactive compounds (BCs) with promising activity for developing natural antioxidants extracts and/or functional food ingredients with several potential health benefits [8]. Proanthocyanins and chlorogenic acid are compounds well-valued in global functional food market [9]. The global market for compounds such as proanthocyanins and chlorogenic acid were valued at USD $198 \mathrm{M}$ in 2019 in the case of the proanthocyanins and will reach $\sim$ USD $280 \mathrm{M}$ and $\sim$ USD $150 \mathrm{M}$ in 2025, respectively [9]. Additionally, these bioactive compounds (BCs) exhibited a great antioxidant activity associated with improved health benefits, playing an important role in the prevention of several chronic diseases. Consequently, this non-compliant BE apple can be an excellent opportunity to develop new add-value products as functional ingredients towards a sustainable and circular bioeconomy.

The growing demand for natural ingredients and the social awareness linked to food loss valorization led to the development of high-added-value bioactive food ingredients with application in pharmaceuticals, cosmetic products, food enrichment and preservatives, supplements and nutraceuticals increasing [10-12]. The utilization of agro-food wastes is an alternative for commercial production of environmentally sustainable, free of harmful chemicals to preserve personal health and safety $[8,9]$ and cost-effective high-value metabolites in a short time. Nonetheless, the development of these new natural antioxidant extracts needs to meet the market demands regarding economic and environmental sustainability [13] and assure, at the same time, consumer safety.

Currently, the green chemistry-based extraction methods could be a better option against the conventional extraction methods (CE) to meet the circular economy goals, avoiding the negative environmental impact of these methods related to high time and energy consumption, and toxic solvents usage [14]. The extraction is an essential step in the production of antioxidant extracts for food ingredients formulation since it is imperative to obtain higher concentration of target compounds while minimizing the concentration of the other compounds that could interfere with the extract quality and stability, which make them undesired in this extract, despite their nutritional value. Moreover, the extraction should be easy, low-cost, harmless, reproducible and suitable for industrial scale-up [15]. Green chemistry-based extraction methods such as microwave-assisted extraction (MAE) and ultrasound-assisted extraction (UAE), has been widely explored for the recovery of polyphenols from different by-products once these methodologies demonstrate higher yield in less time while reducing solvent and energy consumption [16]. UAE requires less extraction time than CE because the contact surface between the solid and liquid phases, increases by partial destruction due to the cavitation process [17]. On the other hand, MAE enables that extraction to be heated by the interaction with the free molecules present, which leads to the destruction of fruit tissue and the release of the BCs into the solvent by the combination of high temperature and pressure. Furthermore, in both methods, the extraction time is shortened to only a few minutes in relation to $1-20 \mathrm{~h}$ with conventional extractions [17].

Until now, to the best of our knowledge, there are no studies applying MAE and UAE to non-compliant BE apples in order to develop natural antioxidant extracts. Notwithstanding, our research group already carried out similar works with non-compliant cherry to produce antioxidant extracts [15]. The main purpose of this research work was compared 
two green extraction techniques (MAE and UAE) with CE (with low and high temperatures) to observe the best technique to produce a natural antioxidant extract rich in polyphenols from non-compliant BE apple for further food applications. Thereupon, other variables such as type of solvent, solvent/mass ratio, time and temperature were not considered for the study since studies of optimization of these parameters for several matrices, including apple pomace and apple peels, were already reported in the literature [18-20]. The solvent used, a mixture of ethanol and water (50:50, v:v), was selected based on results obtained in previous studies with different mixture percentage of ethanol in the mixture. The solvent ethanol and water (50:50, v:v) is considered (i) food grade, (ii) environmentally friendly, (iii) could be reused in the process, and finally (iv) this mixture is one of the most common mixtures of solvents used to produce extracts rich in phenolic compounds [15]. The four different antioxidant extracts developed were evaluated regarding their phenolic compounds composition and antioxidant capacity using chemical in vitro assays.

\section{Results and Discussion}

\subsection{Total Phenolic Content}

BE apples are highly heterogeneous materials, composed of well-balanced macronutrients (mainly proteins and carbohydrates), micronutrients (minerals and vitamins) and phytochemicals, such as phenolic acids, flavonoids and dihydrochalcone.

In Table 1 are presented the results of the TPC from the BE apple extracts, and concentrations varied between $2.82 \pm 0.21$ and $4.64 \pm 0.64 \mathrm{mg}$ GAE/g of DE depending on the extraction methodology. The extracts with the highest TPC were obtained in CET (4.64 $\pm 0.64 \mathrm{mg} \mathrm{GAE} / \mathrm{g}$ of DE) and MAE $(4.44 \pm 0.32 \mathrm{mg} \mathrm{GAE} / \mathrm{g}$ of DE) without statistically significant differences $(p>0.05)$ followed by CE $(2.95 \pm 0.31 \mathrm{mg} \mathrm{GAE} / \mathrm{g}$ of $\mathrm{DE})$ and $\mathrm{UAE}(2.82 \pm 0.21 \mathrm{mg}$ GAE$/ \mathrm{g}$ of DE) $(p>0.05)$.

Table 1. The Total Phenolic Content (TPC) in 'Bravo de Esmolfe' apple extracts. Values are represented by the average \pm standard deviation. Different letters in row $(a, b)$ mean significant differences between extraction methodologies, determined by Tukey's test $(p<0.05)$.

\begin{tabular}{cc}
\hline $\begin{array}{c}\text { BE Apple } \\
\text { Extracts }\end{array}$ & $\begin{array}{c}\text { TPC } \\
\text { (mg GAE/g DE) }\end{array}$ \\
\hline CE & $2.95 \pm 0.31^{\mathrm{b}}$ \\
CET & $4.64 \pm 0.64^{\mathrm{a}}$ \\
MAE & $4.44 \pm 0.32^{\mathrm{a}}$ \\
UAE & $2.82 \pm 0.21^{\mathrm{b}}$ \\
\hline
\end{tabular}

The methodologies with higher temperature extraction (CET and MAE) were shown to generate BE apple extracts with higher TPC values, while CE and UAE showed the lowest values. Since the extracting solvent, solvent/sample ratio and moisture content in the fruit were the same, it can be concluded that the high temperature reached in MAE and CET $\left(80^{\circ} \mathrm{C}\right)$ was responsible for the highest values of TPC. The temperature might soften the fruit tissue and weaken the polyphenols-protein and polyphenols-polysaccharide interaction, leading to disruption and consequent migration of phenolic compounds to the solvent [21]. Similarly, several works with apple pomace and other fruits have confirmed that the use of high temperatures promotes an increase of the solute solubility in the solvent, leading to a higher mass transfer rate and, consequently, higher content of polyphenols [21,22]. For instance, Blidi, et al. [23] found that CET with $50 \%$ of ethanol at $80{ }^{\circ} \mathrm{C}$, with a solvent/ sample ratio $100 \mathrm{~mL} / \mathrm{g}$, provided the extract from Red Delicious waste peels with higher TPC than $\mathrm{CE}$. However, the heating created in MAE has been reported to present higher advantages than CET since the process of energy transmission allowed to get homogeneous heating of the sample, shorter extraction time and lower power energy to perform the extraction [24]. Indeed, the study carried out by Bai, et al. [25] demonstrated that MAE provided higher TPC than CE (reflux without temperature), and then UAE. Several studies report that UAE was developed to improve the yield of phenolic compounds extraction and other 
bioactive compounds compared to CE methods [26], including studies with apples and apple by-products report the UAE extracted higher TPC than in CE [26,27]. For instance, Mendoza-Wilson et al. [28] obtained an aqueous extract with ultrasonic bath from Red Delicious apples with great polyphenols content $(16.36 \mathrm{mg} / \mathrm{g}$ dry weight) comparing to $\mathrm{CE}$. The enhancement of UAE is due to the intensification of mass transfer and solvent penetration into the solute, as well as cell disruption due to the cavitation process, while the MAE allows rapid, efficient and homogeneous heating, which also results in the expansion and rupture of cell walls and increased solvent penetration. However, in this study, the TPC values obtained in the extract from UAE were not statistically different $(p>0.05)$ from the $\mathrm{CE}$. The reason for the absence of differences could be related to the fact that, in this study, indirect UAE was used to proceed with extraction, i.e., an ultrasonic bath was used (Figure 4). Accordingly, the ultrasonic bath was used so that the cavitation process does not act directly on the sample and solvent, decreasing the cell disruption.

In short, the higher values of TPC of BE apple extracts were obtained by CET and MAE. Nevertheless, the TPC only represented about $0.46 \%$ of the total BE apple extract yield. For this reason, it is feasible to conclude that other compounds like carbohydrates of which insoluble fibres, minerals and organic acids were simultaneously extracted, account for the total extract mass (analysis not considered for this study) [29]. The Folin-Ciocalteu method is based on an electron-transfer reaction, and the reagent may be reduced by other molecules present in the extracts, mainly sugars and proteins causing some interference in the measurement, leading to some interference in the final measurements [30]. Moreover, this method is a total quantification and only provides an estimate of total polyphenols content present; therefore, a detailed analysis of individual phenolic compounds was performed.

\subsection{Phenolic Compounds Profile and Quantification}

The qualitative and quantitative profile of phenolic compounds present in the BE apple extracts is of major interest for valorizing their potential since the type and the structure of present phenolics may predetermine extract's antioxidant and other activities that can be responsible for health claims. The BE apple antioxidant extracts were analyzed by mass spectrometry for a more complete characterization of phenolic compounds profile (Table 2). As a result, five different chemical classes of phenolic compounds, including hydroxycinnamic acids, flavanols, flavonols, hydroxybenzoic acids and dihydrochalcones, were detected. Thus, a total of 23 compounds were identified on the most promising BE apple extracts (from MAE and CET), while in CE and UAE only eight phenolic compounds were identified.

The main phenolic acids detected belong to hydroxycinnamic acids group, of which caffeoylquinic acids (CQAs) with a molecular ion [M-H]- at $m / z 353$, and coumaroylquinic acid (CoQAs) with a molecular ion [M-H]- at $m / z 337$, were widely distributed in apples, in particular in the BE apple variety [3]. The three main compounds belonging to CQAs were 3-caffeoylquinic acid (neochlorogenic acid), 5-caffeoylquinic acid (chlorogenic acid) and 4-caffeoylquinic acid (cryptochlorogenic acid). The molecular ion [M-H]- of CQAs was consistent with their molecular formula of $\mathrm{C}_{16} \mathrm{H}_{18} \mathrm{O}_{9}$ and since those molecules can suffer esterification at different positions of quinic acid moiety, different isomers are detected. Regarding the CoQAs, three different isomers (3-CoQAs, 4-CoQAs and 5-CoQAs) were found in BE apple extracts, showing the typical fragments of the p-coumaric acid $\mathrm{m} / \mathrm{z} 163$ and 119 and the loss of quinic acid $(m / z$ 191). Same CQAs and CoQAs derivatives were already reported in other works where apple extracts were characterized [1], particularly, Pires et al. [3] who detected 5-CQAs, 4-CQAs, 5-CoQAs and 4-CoQAs in BE apple dried powder. Among the other group of phenolic acids, hydroxybenzoic acids, only one compound with an $\mathrm{m} / \mathrm{z} 315$ was detected, and in the MS/MS fragments, it produced a base peak at $\mathrm{m} / \mathrm{z} 153$ linked to a loss of sugar with $162 \mathrm{Da}$, corresponding to protocatechuic acid aglycone. This is the first time that protocatechuic acid was identified in BE apple to the best of our knowledge. 
Table 2. Phenolic compounds identified (or tentatively identified) by LC-ESI-UHR-QqTOF-MS in different 'Bravo de Esmolfe' apple extracts.

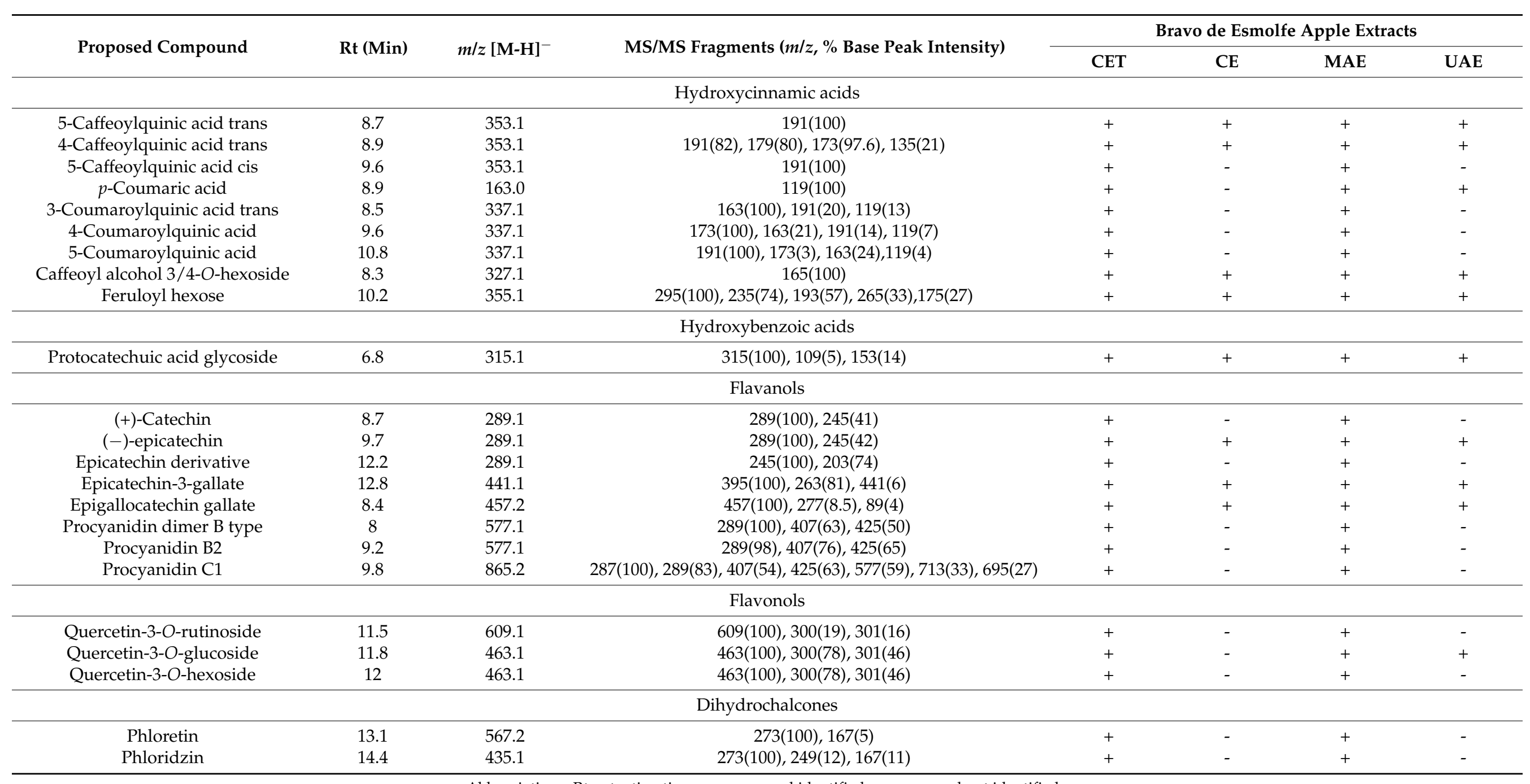

Abbreviations: Rt, retention time; +, compound identified; -. compound not identified. 
The flavanols are the major class of apple phenolic compound [28], a total of eightwere identified in BE apple extracts. In the extracts produced by $\mathrm{CE}$ and UAE only five flavanols were detected. $(+)$-Catechin and (-)-epicatechin $(\mathrm{m} / \mathrm{z} 289.1)$ were identified by comparison of retention time and fragmentation spectra with authentic standards. Epicatechin-3-gallate and epicatechin-gallate $(m / z 441.1$ and 457.2, respectively) were identified based on their MS/MS fragmentation and by comparison with the literature [31]. Two B-type C-type (epi)catechin dimers were identified regarding the procyanidins at $m / z 577.1$ and $m / z$ 865.2, respectively. The fragmentation pattern of these molecules is consistent with previously reported data indicating the possibility of one of these dimers being procyanidin B2 and the C-type being procyanidin C1 [3]. These procyanidins have been consistently reported as the most representative in apples. Furthermore, works of Pires et al. [3] with dried BE apple identified, in methanolic extracts, these compounds and other B-type dimers, trimers and one tetramer, and works of Feliciano et al. [1] with fresh BE apple identified only two B-type of procyanidins (B1 and B2).

Only three quercetin derivatives were identified among flavonols: quercetin-3-Oglucoside, quercetin-3-O-rutinoside and quercetin-3-O-hexoside, where the first one was also detected in exotic and Portuguese varieties, for instance, in BE apple [1]. Furthermore, they report two more flavonols: kaempferol-3-glucoside and quercetin-3-rhamnoside.

Dihydrochalcones are one of the most recognized apple polyphenols group and two compounds from this group are detected in the extracts, phloretin and phloridzin. These compounds have been already reported in BE apple by Pires et al. [3]. However, these compounds were only detected in the CET and MAE extracts.

As previously mentioned, some of the extraction methodologies used to produce the different $\mathrm{BE}$ apple extracts showed no effectiveness in recovering some of the apple phenolic compounds, as LC-ESI-QqTOF-HRMS did not detect them in the extracts. For instance, in BE apple, the CE extract showed only eight phenolic compounds among the total 23 identified demonstrating the lower number of phenolic compounds present in the extract. The higher phenolic variability detected in MAE and CET extracts is consistent with the results obtained in TPC. The temperature increasing in conventional extraction (from 25 to $80^{\circ} \mathrm{C}$ ) had a positive impact in polyphenols extraction, since in CET the total 23 phenolic compounds were identified. Additionally, MAE extract showed also the same phenolic compounds identified. Thus, the CET and MAE reveal to be more promising methodologies for extraction of higher variability of phenolic compounds from BE apple. Regarding the UAE, the results were similar to CE, which corroborate the TPC values.

Therefore, the compounds with higher intensity identified in each BE apple extract were quantified by HPLC-DAD, and are summarized in Table 3. The extracts obtained by CET and MAE, despite the differences observed in the amounts of each phenolic compound, exhibited a similar chromatographic profile, as expected, due to the previous identification reported. Instead, the extracts obtained by CE and UAE exhibited only a few phenolic compounds quantified.

The major phenolics found in the extracts were chlorogenic acid, (-)-epicatechin, (+)-catechin, procyanidin B2 and C1, p-coumaroylquinic acid and phloridzin. All of them are usually reported in apples [32], mainly in BE variety [1,3]. The MAE extract had the highest contents of chlorogenic acid $(0.48 \pm 0.07 \mathrm{mg} / \mathrm{g} \mathrm{DE})$, cryptochlorogenic acid $(0.12 \pm 0.01 \mathrm{mg} / \mathrm{g} \mathrm{DE})$ procyanidin B2 $(0.12 \pm 0.01)$, procyanidin C1 $(0.12 \pm 0.01 \mathrm{mg} / \mathrm{g} \mathrm{DE}$ $(p>0.05)$. Additionally, no significant differences $(p>0.05)$ were found between MAE and CET in terms of $p$-coumaroylquinic acid, $p$-coumaric, (+)-catechin, (-)-epicatechin-3gallate, (-)-epicatechin and quercetin-3-rutinoside contents. Therefore, these phenolics variations are in accordance with the TPC results (Table 1), and no significant differences were observed between MAE and CET. Other compounds that occur naturally in apples and associated with several health-promoting effects are the dihydrochalcones phloridzin and phloretin [33]. In this study, these compounds were only recovered by CET and MAE and were the only compounds found at the highest amount in CET than in MAE extract: phloridzin $(0.21 \pm 0.03 \mathrm{mg} / \mathrm{g} \mathrm{DE})$ and phloretin $(0.11 \pm 0.01 \mathrm{mg} / \mathrm{g} \mathrm{DE})(p<0.05)$. Usually, 
this dihydrochalcone is found in greater quantities in the peel than in flesh apple, and the amount of phloridzin is higher than phloretin [33], which are in agreement with our results. Previous works with BE apple polyphenols characterization reported only phloridzin in BE apple [1], although works of Pires et al. [3] reported both phloridzin and phloretin.

The application of conventional methods with higher temperatures (CET) involves longer periods at high temperature than MAE, leading to the possibility of oxidation and hydrolysis of phenolic compounds [34]. However, the higher temperature used in CET could explain the significant higher extraction yields reported to the phloridzin, phloretin, $(+)$-catechin and (-)-epicatechin compared to MAE extract.

According to a previous work that observes the impact of different extraction parameters on extraction yields of the main phenolic compounds of apple skins, only the temperature (an increase from 25 to $50^{\circ} \mathrm{C}$ ) was a significant positive effect for the extraction of (-)-epicatechin, procyanidin B2, phloridzin and their derivatives [35].

Table 3. Quantification of main phenolic compounds (mg/g DE) in different extracts of BE apples by HPLC-DAD. Values are represented by the average \pm standard deviation. Different letters in the row $(a, b, c)$ mean significant differences between extraction techniques, determined by Tukey's test $(p<0.05)$.

\begin{tabular}{|c|c|c|c|c|c|}
\hline \multirow{2}{*}{\multicolumn{2}{|c|}{ Phenolic Compound }} & \multicolumn{4}{|c|}{ Bravo de Esmolfe Apple Extracts } \\
\hline & & CE & CET & MAE & UAE \\
\hline \multicolumn{6}{|c|}{ Hydroxycinnamic Acids } \\
\hline 3 & Chlorogenic Acid & $0.11 \pm 0.01^{\mathrm{c}}$ & $0.34 \pm 0.05^{b}$ & $0.48 \pm 0.07^{\mathrm{a}}$ & $0.12 \pm 0.01^{\mathrm{c}}$ \\
\hline 4 & Cryptochlorogenic Acid & $0.05 \pm 0.00^{b}$ & $0.08 \pm 0.02^{b}$ & $0.12 \pm 0.01^{\mathrm{a}}$ & $0.05 \pm 0.01^{b}$ \\
\hline 2 & p-Coumaroylquinic acid & $0.05 \pm 0.01^{\mathrm{c}}$ & $0.19 \pm 0.01^{\mathrm{a}}$ & $0.18 \pm 0.01^{\mathrm{a}}$ & $0.07 \pm 0.00^{b}$ \\
\hline 1 & $\mathrm{p}$-Coumaric acid & - & $0.10 \pm 0.01^{\mathrm{a}}$ & $0.09 \pm 0.02^{\mathrm{a}}$ & $0.04 \pm 0.02^{\mathrm{a}}$ \\
\hline \multicolumn{6}{|c|}{ Flavanols } \\
\hline 5 & $(+)$-Catechin & - & $0.19 \pm 0.02^{\mathrm{a}}$ & $0.18 \pm 0.03^{\mathrm{a}}$ & - \\
\hline 6 & (-)-epicatechin & $0.11 \pm 0.01^{\mathrm{a}}$ & $0.34 \pm 0.02^{\mathrm{a}}$ & $0.30 \pm 0.02^{\mathrm{a}}$ & $0.10 \pm 0.01^{\mathrm{a}}$ \\
\hline 7 & (-)-epicatechin-3-gallate & $0.05 \pm 0.02^{\mathrm{a}}$ & $0.10 \pm 0.01^{\mathrm{a}}$ & $0.10 \pm 0.02^{\mathrm{a}}$ & $0.06 \pm 0.02^{\mathrm{a}}$ \\
\hline 8 & Procyanidin B2 & - & $0.09 \pm 0.01^{b}$ & $0.11 \pm 0.01^{\mathrm{a}}$ & - \\
\hline 9 & Procyanidin C1 & - & $0.05 \pm 0.02^{b}$ & $0.12 \pm 0.01^{\mathrm{a}}$ & - \\
\hline \multicolumn{6}{|c|}{ Flavonols } \\
\hline 10 & Quercetin-3-rutinoside & - & $0.09 \pm 0.01^{\mathrm{a}}$ & $0.10 \pm 0.01^{\mathrm{a}}$ & - \\
\hline \multicolumn{6}{|c|}{ Dihydrochalcones } \\
\hline 11 & Phloretin & - & $0.11 \pm 0.01^{\mathrm{a}}$ & $0.07 \pm 0.00^{b}$ & - \\
\hline 12 & Phloridzin & - & $0.21 \pm 0.03^{\mathrm{a}}$ & $0.13 \pm 0.01^{b}$ & - \\
\hline
\end{tabular}

Thus, we may assume that MAE is generally more efficient in phenolics extraction than CET in this type of fruits. Furthermore, MAE consumes less energy and time for the extraction of these compounds. UAE and CE, in agreement with previous results of TPC, showed a smaller number of compounds proving that these methodologies are less efficient for phenolic compounds extraction in apples. The hydroxycinnamic acids are the main class of compounds recovered with these extraction methodologies, being the chlorogenic acid the higher compound $(0.11 \pm 0.01 \mathrm{mg} / \mathrm{g}$ DE) recovered without significant differences between CE and UAE $(p<0.05)$. The $(-)$-epicatechin and $(-)$-epicatechin-3-gallate were the only two flavonoids recovered with these methodologies without significant difference $(p>0.05)$. Additionally, the HPLC-DAD profile of extracts obtained by UAE showed a potential degradation of some BCs by decreasing compounds intensity. This fact could be explained by the hot spots generated during bubble collapse that do not cause heat damage to thermal sensitive compounds. However, it should be noted that ultrasonic irradiation for periods longer than about $5 \mathrm{~min}$ at high ultrasonic power may generate heat, and this can cause some degradation in phenolic compounds. Saleh et al. [34] proved that, even under temperature control, prolonged sonication could lead to some degradation of the 
targeted compounds, revealing to be an important parameter that should be taken into consideration for ultrasonic extraction procedures.

In a previous work with BE apple from Mangualde region purchased in 2006, eight phenolic compounds were quantified, and chlorogenic acid and (-)-epicatechin were the two most representative compounds with $9.11 \pm 0.81$ and $8.19 \pm 0.51 \mathrm{mg} / 100 \mathrm{~g}$ fresh apple, respectively [1]. However, despite Serra et al. [4] having observed precisely the same compounds reported in this previous study to BE apple purchased in 2007 also from Mangualde, they observed a higher amount of (-)-epicatechin $(12.80 \pm 0.21 \mathrm{mg} / 100 \mathrm{~g}$ fresh apple) and chlorogenic acid (17.02 $\pm 0.44 \mathrm{mg} / 100 \mathrm{~g}$ fresh apple). On the other hand, Pires et al. [3] observed that chlorogenic acid was the most abundant phenolic compound in hydromethanolic extracts of dried BE apple. Thus, these polyphenols concentrations may depend on many factors, such as plant genotype, maturation stage, climatic conditions, agronomic practices, storage and processing [36-40]. Therefore, it is necessary take into consideration these factors for future reproducibility in the bioactive extracts production. However, pre-harvest factors optimization may be difficult due to varying environmental conditions and differences in farm management practices [41]. On the other hand, the polyphenols concentration is different in different parts of the plant (pulp, peel, seed, stem). Górnaś et al [39] observed that peel and pulp have less polyphenols concentration, while seeds and stems have the highest content of polyphenols. However, the peels and pulps represent about $95 \%$ of the total apple weight, whereas seeds and stems represent about $2 \%$ and $0.5 \%$, respectively. Therefore, the valorization of pulp and peel reflect a greater impact given their greater amount. However, depending on the amount of each part of the plant used to obtain the extract, the content and type of phenolic compounds obtained can vary significantly.

The richness in polyphenols from different families found in BE apple emphasizes the importance of recover value from non-compliant fruit, since, although not having acceptable parameters for direct sale in fresh food chain, it is still rich in phenolic compounds. Moreover, the utilization of the regional fruit variety supports the biodiversity preservation and boosts the local bioeconomy by promoting the commercialization of new products deriving from regional varieties, thereby reducing the carbon footprint in the environment due to the valorization of food losses [42].

It should be noted that the values of TPC obtained by the Folin-Ciocalteu method (Table 1) were higher than that sum of all phenolic compounds quantified by liquid chromatography. These differences could be explained by some of the minor peaks, which could not be quantified, as they were under detection range and because the Folin-Ciocalteu's reagent can also react with polysaccharides and proteins given an overestimation of total phenolic content [30]. Furthermore, the TPC results are expressed based in gallic acid equivalents, and on HPLC results, it is quantified the exact amount of each phenolic compound by the pure standard.

\subsection{Antioxidant Activity}

In recent years, the interest from food industries in natural antioxidants has increased, due to several studies have shown possible adverse effects that may be related to the consumption of synthetic antioxidants [43,44]. On the other hand, regular consumption of antioxidants is associated with a reduced risk of chronic diseases and the natural ones could replace synthetic antioxidants in foodstuffs [45]. Different plant materials are known to be a natural source of antioxidants, such as herbs, seeds, fruits, vegetables and also their byproducts. The interest in these natural antioxidants is not only due to their biological value but also to their economic impact, as most of them may be extracted from food by-products and under-exploited plant parts or species. In order to evaluate the total antioxidant activity of the extracts, three different methods were used, due to the absence of a unique methodology able to reflect the total antioxidant activity of a complex matrix, since the antioxidant activity of food and ingredients is determined by a mixture of different phenolic compounds with different action mechanisms [46]. ABTS and/or DPPH are among the 
most popular colourimetric methods to evaluate foods' total antioxidant activity. However, ABTS applies to both hydrophilic and lipophilic antioxidants, whereas DPPH applies to hydrophobic [47]. ORAC method has been reported by different authors as a more relevant antioxidant method because it engages a biological radical (peroxyl) source and is a very high sensitivity, mainly used to measure the activity of hydrophilic antioxidants compounds [48]. The antioxidant activity values of BE apple extracts, measured by the three different methods (ORAC, ABTS, DPPH) are shown in Figure 1. The values ranged from $6.74 \pm 0.42$ to $17.26 \pm 0.50 \mathrm{TE} / \mathrm{g} \mathrm{DE}$, from $1.73 \pm 0.07$ to $4.42 \pm 0.11 \mathrm{AAE} / \mathrm{g} \mathrm{DE}$, and from $2.69 \pm 0.26$ to $5.11 \pm 0.13 \mathrm{mg}$ TE/g DE, respectively for ORAC, ABTS and DPPH.

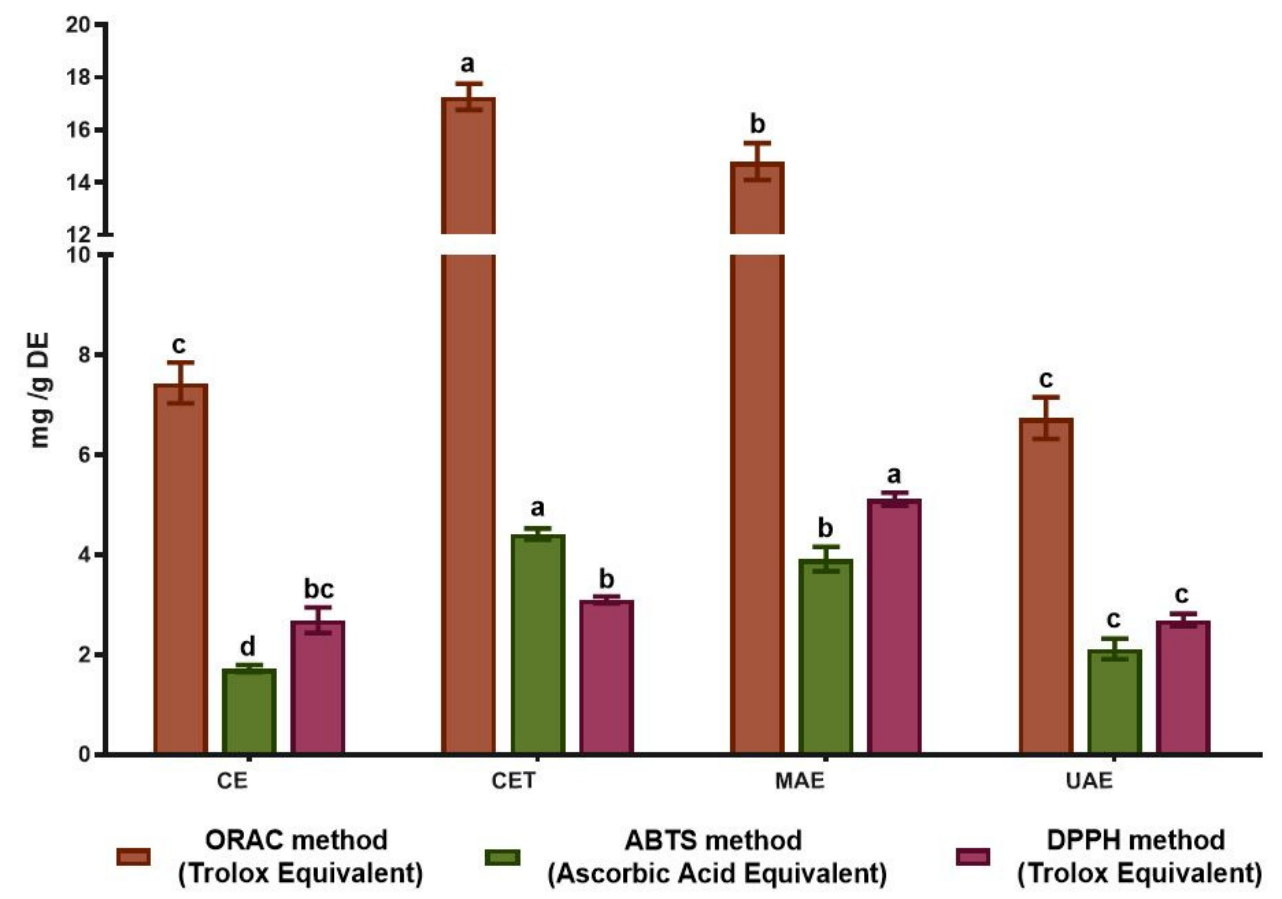

Figure 1. Antioxidant activity of different Bravo de Esmolfe apple extracts by ORAC method (expressed as mg TE/g DE), ABTS method (expressed as mg AAE/g DE) and DPPH method (expressed as $\mathrm{mg}$ TE/g DE). Different letters ( $\mathrm{a}, \mathrm{b}, \mathrm{c}, \mathrm{d})$ mean significant differences between extraction techniques in each antioxidant assay (same color in the graph), determined by Tukey's post-hoc test $(p<0.05)$.

On the ORAC assay, the BE apple extracts obtained by CET showed the highest antioxidant activity $(17.26 \pm 0.50 \mathrm{mg}$ TE/g DE) $(p<0.05)$, followed by MAE $(14.80 \pm 0.70 \mathrm{mg}$ TE/g DE) $(p<0.05)$. The BE apple extracts obtained by CE $(7.44 \pm 0.41 \mathrm{mg} \mathrm{TE} / \mathrm{g} \mathrm{DM})$ and UAE (6.74 $\pm 0.42 \mathrm{mg} \mathrm{TE} / \mathrm{g}$ DE) showed the lower values, without significant differences $(p>0.05)$. The ORAC values showed a high positive correlation with the previous values of TPC $\left(R^{2}=0.9886\right)$, and the ORAC values were much higher than the values of DPPH and ABTS. This kind of differences in values determined by the different methods was previously reported in our work that aims to develop natural antioxidant extracts from cherries [15] and probably arise from the different chemical structures of used radicals and the distinct mechanisms involved during each methodology. In ABTS and DPPH method, it was evaluated the Single-electron transfer (SET) capacity, and in the ORAC assay the hydrogen atom transfer (HAT) capacity [49]. Moreover, Serra et al. [2] also reported high positive correlation between ORAC and TPC values $\left(R^{2}=0.834\right)$ in BE apple extract obtained with $80 \%$ acetone/water.

Concerning the ABTS results, the BE apple extracts obtained by CET presented higher antioxidant activity $(4.42 \pm 0.11 \mathrm{mg} \mathrm{AAE} / \mathrm{g} \mathrm{DE})(p<0.05)$, followed by MAE $(3.92 \pm 0.25 \mathrm{mg} \mathrm{AAE} / \mathrm{g} \mathrm{DE})(p<0.05)$, and the lowest values were attributed to UAE $(2.12 \pm 0.21 \mathrm{mg} \mathrm{AAE} / \mathrm{g} \mathrm{DE})$ and $\mathrm{CE}(1.73 \pm 0.07 \mathrm{mg} \mathrm{AAE} / \mathrm{g} \mathrm{DE})(p>0.05)$. Likewise, 
in the ORAC method, CET followed by MAE BE apple extracts showed the highest antioxidant activity in the ABTS method, which is positively correlated $\left(R^{2}=0.9644\right)$ with the higher TPC reported above. Furthermore, this behaviour has also been reported by Gómez-García et al. [50] and Dias et al. [51], who demonstrated a good correlation between total phenolic compounds and the antioxidant activity of melon peels and strawberry tree extracts, respectively, indicating that phenolic compounds are major contributors to antioxidant activity.

In the results of DPPH free radicals inhibition, it was observed that MAE presented higher antioxidant activity $(5.11 \pm 0.13 \mathrm{mg} \mathrm{TE} / \mathrm{g} \mathrm{DE})(p<0.05)$, followed by CET $(3.10 \pm 0.07 \mathrm{mg} \mathrm{TE} / \mathrm{g} \mathrm{DE})(p<0.05)$, and CE $(2.70 \pm 0.12 \mathrm{mg} \mathrm{TE} / \mathrm{g} \mathrm{DE})$ and UAE $(2.69 \pm 0.26 \mathrm{mg}$ TE/g DE), which showed the lowest values $(p>0.05)$. The values obtained in the DPPH method did not correlate with the TPC $\left(\mathrm{R}^{2}=0.4097\right)$. This could be due to the DPPH method being more efficient to measure less polar compounds, since these radicals only are dissolved in an organic solvent (in this work was used methanol) and therefore evaluates hydrophobic systems [52]. Instead observed in other two methods, in the DDPH method, MAE extract achieved higher values than the CET extract, and this could be explained by ORAC and ABTS radicals reacting energetically with hydrogendonors, although DPPH is more selective in the reaction with hydrogen-donors than ABTS, which can interact greatly with some of the phenolic compounds recovered in greater quantity (CGAs, procyanidins and quercetin-3-rutinoside) that apparently possess a greater antioxidant capacity with this method [53].

The antioxidant values agree with the phenolic compounds present in each extract (HPLC values) since the extracts with more phenolic compounds (CET and MAE) shows more antioxidant activity than UAE and CE. Furthermore, the higher antioxidant activity of CET (in ABTS and ORAC method) could be related with the compounds more abundant in this extract $((+)$-catechin, $(-)$-epicatechin, phloridzin and phloretin once molecules show high correlation with the ORAC method [2]. On the other hand, the MAE extraction could be a selective method to produce an extract with higher antioxidant activity and rich in CGAs and procyanidins, which are compounds well valued in the global functional food market and with human health benefits reported [9]. Therefore, it was suggested that the differences in BE extracts' antioxidant activity depend on the composition of polyphenolic compounds and the structure of some compounds, particularly the distribution of hydroxyl groups in the molecules.

To our knowledge, there are no research studies about using non-compliant BE apples or other varieties to produce functional extracts with a proven antioxidant activity using green methodologies such as MAE and UAE and using CE extraction with ethanol and water mixtures. However, Pires et al. [3] evaluated the antioxidant activity of BE apple dried powder (extract obtained with methanol $80 \%$ at $25^{\circ} \mathrm{C}$ during $1 \mathrm{~h}$ ) and reported a $\mathrm{EC}_{50}=0.71 \pm 0.05 \mathrm{mg} / \mathrm{mL}$ in DPPH assay and Serra et al. [2] reported an ORAC value of $1503 \pm 48 \mu \mathrm{mol} \mathrm{TE} / 100 \mathrm{~g}$ for BE apple (extracted with acetone $80 \%$ at $25^{\circ} \mathrm{C}$ during $8 \mathrm{~min}$ ).

These relevant results of antioxidant activity on $\mathrm{BE}$ apple extracts are in agreement with the higher content of polyphenol compounds and show the importance of using non-compliant fruit as a natural source of antioxidants. These "ugly fruit" are a low-cost resource that could be used to develop new food ingredients for the food industry, such as natural antioxidant extracts. On the other hand, the use of non-compliant fruit represents a solution with low environmental impact since it uses value-added food and promotes a sustainable bio-economy [42].

\subsection{Principal Component Analysis}

A principal component analysis (PCA) was performed to achieve an overall vision of the different extracts and identify a possible relationship between all parameters analyzed in this study. The variables considered in PCA for each extract are described in Table 4. 
Table 4. Description of the 16 variables considered in PCA for BE apple extracts.

\begin{tabular}{cc}
\hline & BE Apple Extracts \\
\hline Number & Variable Designation \\
\hline 1 & Total Phenolic Content \\
2 & ABTS method \\
3 & DPPH method \\
4 & ORAC method \\
5 & Chlorogenic acid \\
6 & Cryptochlorogenic acid \\
7 & p-Coumaroylquinic acid \\
8 & -Coumaric acid \\
9 & (+)-Catechin \\
10 & $(-)$-epicatechin \\
11 & Epicatechin-3-gallate \\
12 & Procyanidin B2 \\
13 & Procyanidin C1 \\
14 & Quercetin-3-rutinoside \\
15 & Phloretin \\
16 & Phloridzin \\
\hline
\end{tabular}

In this analysis, 16 variables were measured in the different BE apple extracts and analyzed by a bidimensional plot (Figure 2). The cumulative percentage of the total variance explained by the first two components was $99.58 \%$. Component 1, which described $87.71 \%$ of the parameters' variability, was positively influenced by all the variables in the study accounting for TPC, which was strongly associated with this component as well p-coumaric, ABTS method and ORAC method. In component 2, which accounted for $11.87 \%$ of the variability, received the main positive contribution from the DPPH method, cryptochlorogenic and chlorogenic acid andprocyanidin $\mathrm{C}$. Through the analysis of Figure 3, it was possible to verify that the TPC (variable 1) is more correlated with ABTS (variable 2) and ORAC (variable 4) method than DPPH (variable 3), and the antioxidant activity measured by ABTS and ORAC is more correlated with flavonoids than phenolic acids, since their structure has higher antioxidant potential reported.

The distribution of BE apple extracts along PC1 and PC2 plot could be divided into three main groups, allowing to understand which variables contributed more to the distribution obtained. The first, which is located on the positive side of the PC1 and PC2, includes the MAE extract; the second, positioned on the positive side of PC1 and the negative side of $\mathrm{PC} 2$, comprises the CET extract; and the third, located on the negative side of PC1 and on the positive side PC2, includes UAE and CE. The CE and UAE extracts are distinguished from the others due to their low content in phenolic compounds as well as antioxidant activity. Due to the analysis of the variables, it was possible to verify that DPPH was correlated with the amount of cryptochlorogenic acid and quercetin-3-rutinoside present in the extracts, due to the nature of these compounds, as they have shown affinity to organic solvents reflecting better results in DPPH method than in $\mathrm{ABTS}^{\circ}$ method.

The MAE and CET exhibited a higher amount of phenolic compounds as well as greater antioxidant activity. In particular, MAE exhibited the highest amount of caffeoylquinic acids, procyanidins and quercetin-3-rutinoside as well as the greatest antioxidant activity in scavenging DPPH. Moreover, this extraction method is distinguished from the CET by its higher contents of phloridzin and phloretin and great antioxidant activity by ORAC and ABTS assays. These results suggest that these compounds could be the major contributors for the ORAC and ABTS values obtained. The use of CET to produce $\mathrm{BE}$ apple extracts showed to be a technique with good results, yet it is more time- and energy-consuming comparatively to MAE. Furthermore, since the MAE are on the positive side of both PCs and MAE application for 1.5 min allowed to obtain a polyphenol-rich extracts with higher antioxidant activity in ORAC. It is possible to conclude that MAE is more efficient than the CET method to produce the BE extracts. One of the most important 
advantages of MAE is that a high-efficiency extraction can be done using only the water content present in the fresh BE apples [54]. Besides this, according to Leadbeater [55] it is possible to have access to higher temperatures easily, safely and in a reproducible manner, decreasing the extraction time needs and improving the purity compared to CET.

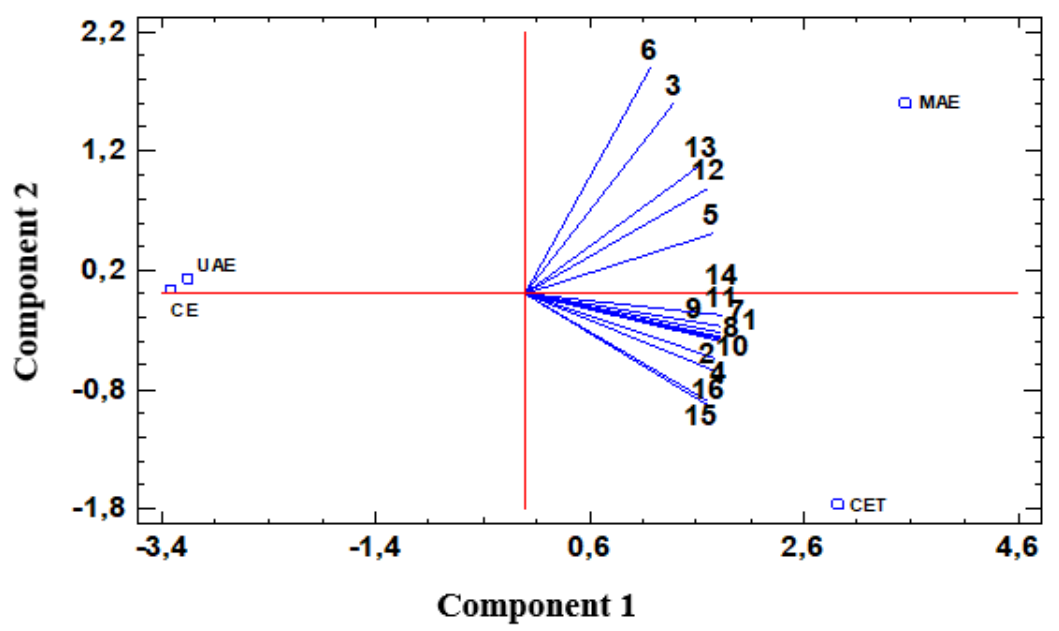

Figure 2. Principal Component analysis (PCA) biplot for the 16 parameters analyzed in Bravo de Esmolfe apple extracts. The first component explained $87.71 \%$ of the variance across the different 'Bravo de Esmolfe' apple extracts and the second component explained $11.87 \%$.

\section{Materials and Methods}

\subsection{Chemicals}

The 2-azinobis-3-ethylbenzothiazoline-6-sulphonic acid (ABTS), 2,2'-azo-bis-(2methylpropionamidine)-dihydrochloride (AAPH), 2,2-diphenyl-1-picrylhydrazyl (DPPH), 3-caffeoylquinic acid, 5-caffeoylquinic acid, ascorbic acid, fluorescein, gallic acid, $p$-coumaric acid, phloretin, sodium carbonate $\left(\mathrm{Na}_{2} \mathrm{CO}_{3}\right)$, trifluoroacetic acid (TFA) and trolox were purchased from Sigma-Aldrich (Sintra, Portugal). (-)-epicatechin, (+)-catechin, phloridzin, procyanidin $\mathrm{B} 2$, procyanidin $\mathrm{C} 1$ and quercetin-3-rutinoside were purchased from Extrasynthése (Genay Cedex, France). Acetonitrile and methanol were purchased from Fischer Scientific (Oeiras, Portugal). Folin-Ciocalteu's reagent and potassium persulfate were purchased from Merck (Algés, Portugal).

\subsection{Plant Material and Preparation of Extracts}

\subsubsection{Plant Material}

Non-compliant apples (Malus domestica) wild variety of 'Bravo de Esmolfe', grown in Oliveira do Hospital (Portugal center interior region), were provided by 'Frutas Agostinho' L from Oliveira do Hospital, Portugal. The apples were stored in a cold room $\left(6^{\circ} \mathrm{C}\right)$ during the analysis time ( 2 weeks). They were washed in cold water for $1 \mathrm{~min}$ and the whole pitted (stems and seeds) taken off. After that, the BE apples were cut in quarters and immediately crushed with a domestic grinder obtaining a pomace (pulp-to-peel ratio 7.7) for the several methods described below.

\subsubsection{Preparation of BE Apple Extracts}

Classical extraction without temperature (CE): An apple pomace sample of $4 \mathrm{~g}$ was mixed with $25 \mathrm{~mL}$ of ethanol/water $(50: 50, v / v)$ and the extraction occurred in a glass shot by stirring (with a magnetic bar) for $1 \mathrm{~h}\left(25^{\circ} \mathrm{C}\right)$.

Conventional extraction with temperature (CET): Extraction using temperature $\left(80 \pm 1^{\circ} \mathrm{C}\right)$ was performed with $4 \mathrm{~g}$ of the apple pomace mixed with $25 \mathrm{~mL}$ of ethanol/water $(50: 50, v / v)$ in a glass shot with stirring during $20 \mathrm{~min}$.

Microwaves-assisted extraction (MAE): A single mode focused microwave reactor (Milestone, Start S Microwave Labstation for Synthesis, Italy, with a rotor SK-12) operating 
at $2450 \mathrm{MHz}$ with adjustable microwave power (Figure 3), without exceeding $80^{\circ} \mathrm{C}$ was used for extraction of $4 \mathrm{~g}$ apple pomace with $25 \mathrm{~mL}$ ethanol/water $(50: 50, v / v)$. The general extraction parameters were: 3 extraction cycles of $30 \mathrm{~s}$ at $1000 \mathrm{~W}$ and stirring- $60 \%$.

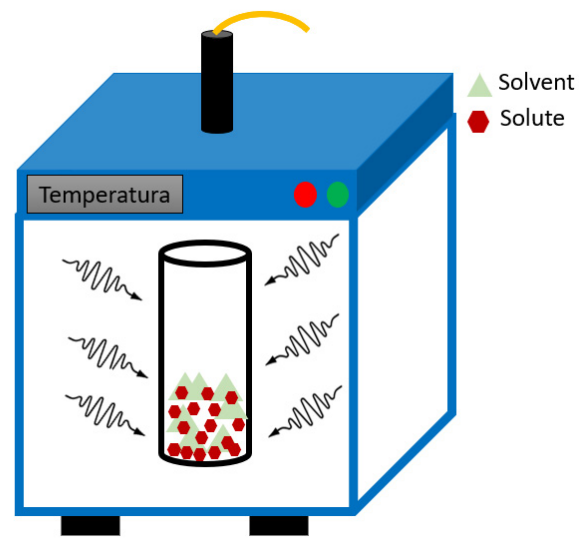

Figure 3. Scheme of microwave reactor for MAE.

Ultrasound-assisted extraction (UAE): was performed with an ultrasound bath (Laborette 17, Fritsch, Germany) (Figure 4) and applied to $4 \mathrm{~g}$ apple pomace mixed with $25 \mathrm{~mL}$ ethanol/water $(50: 50, v / v)$. The sonication time was $30 \mathrm{~min}$ with $120 \mathrm{~W}$ application power and frequency range $50-60 \mathrm{~Hz}$ with temperature control $\left(25^{\circ} \mathrm{C}\right)$.

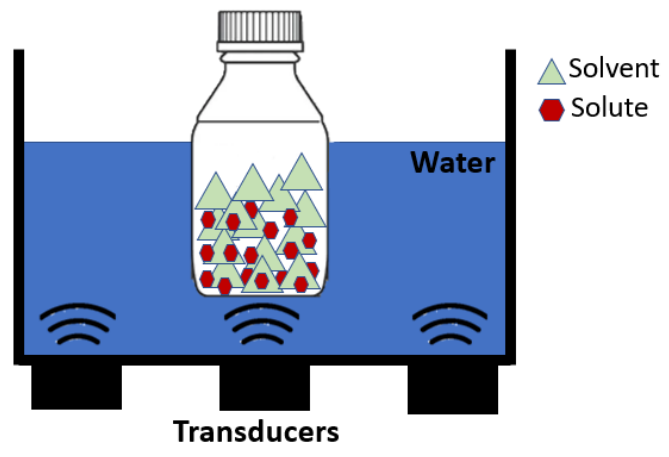

Figure 4. Scheme of the ultrasonic bath for UAE.

After the different extraction methods, all the extracts were centrifuged (K241, Centurion Scientific Ltd., Stoughton, UK) at $2600 \mathrm{G}$ for $20 \mathrm{~min}$. The ethanol fraction from the supernatant was evaporated by rotary evaporator $\left(40{ }^{\circ} \mathrm{C}, 175 \mathrm{mbar}\right)$ and the remaining aqueous extract was dried by freeze-drying (LyoQuest-85, Telstar, Portugal). Lastly, the dry extracts were stored in an aluminium foil bag and kept in a desiccator during the analysis time. All extraction techniques were done in three independent extractions.

\subsection{Total Phenolic Content}

The total phenolic content (TPC) was spectrophotometrically measured for all the different extracts (CE, CET, UAE and MAE), according the Folin-Ciocalteu method [56] with some modifications. Briefly, $20 \mu \mathrm{L}$ of extract (previously dissolved in distilled water at $50 \mathrm{mg} / \mathrm{mL})$ and $80 \mu \mathrm{L}$ of Folin-Ciocalteu reagent $(10 \% v / v)$ were mixed in a 96-well microplate (Nunc ${ }^{\mathrm{TM}}$, Thermo Fisher Scientific Inc., Waltham, MA, USA). Thereafter, $100 \mu \mathrm{L}$ of sodium carbonate $(7.5 \%(\mathrm{~m} / \mathrm{v}))$ was added. Gallic acid was used as a standard for the calibration curve $\left(0.010-0.125 \mathrm{mg} / \mathrm{mL}, \mathrm{y}=6.0796 \mathrm{x}+0.1314, \mathrm{R}^{2}=0.9999\right)$ and the microplate was incubated in the dark at room temperature $\left(25^{\circ} \mathrm{C}\right)$ for $1 \mathrm{~h}$. Finally, the absorbance was measured at $750 \mathrm{~nm}$ (Multiskan GO Microplate Spectrophotometer, Thermo Fisher Scientific Inc., Waltham, MA, USA) and the results were expressed as milligrams equivalent 
of gallic acid per gram of dry extract (mg GAE/g DE). Analyses were performed in triplicate for each extract.

\subsection{Phenolic Compounds Identification by LC-ESI-QqTOF-HRMS}

A qualitative characterization of the phenolic compounds present in BE apple antioxidant extracts was carried out by liquid chromatography electrospray ionization quadrupole time-of-flight mass spectrometry (LC-ESI-QqTOF-HRMS) following the methodology described by Vilas-Boas et al. [15]. Firstly, the extracts were dissolved in ultrapure water $(5 \mathrm{mg} / \mathrm{mL}$ ) and the separation was performed in a UHPLC UltiMate 3000 Dionex (Thermo Fisher Scientific Inc., Waltham, MA, USA), coupled to an ultra-high-resolution Qq-timeof-flight (UHR-QqTOF) mass spectrometer with 50,000 full-sensitivity resolution (FSR) (Impact II, Bruker Daltonics, Bremen, Germany), using an Acclaim RSLC 120 C18 column $(100 \mathrm{~mm} \times 2.1 \mathrm{~mm}, 2.2 \mu \mathrm{m}$ ) (Dionex, Thermo Fisher Scientific Inc., Waltham, MA, USA). The identification was based on standard solutions retention time and mass spectra, when available, and the other peaks were tentatively identified based on the literature, and their elemental composition was confirmed through the accurate mass measurement (within $5 \mathrm{mDa}$ of the assigned elemental composition) and mSigma values of $<20$. One independent analysis was performed in each of the triplicate extracts obtained for each different methodology.

\subsection{Phenolic Compounds Quantification by HPLC}

The main phenolic compounds identified (Section 3.4) were quantified using a HPLCDAD (Waters Alliance e2695 separation module system interfaced with a photodiode array UV/Vis detector 2998 (PDA 190-600 nm) (Waters, Mildford, CT, USA)) according Vilas-Boas et al. [15]. Detection was performed at $280 \mathrm{~nm}, 320 \mathrm{~nm}, 350 \mathrm{~nm}$ and $360 \mathrm{~nm}$, and the data acquisition and analysis were accomplished with Software Empower 3. Quantification was performed through external calibration curves constructed with pure standards (cryptochlorogenic acid, chlorogenic acid, (-)-epicatechin, (+)-catechin, quercetin-3rutinoside, $\mathrm{p}$-coumaric acid, procyanidin $\mathrm{B} 2$, procyanidin $\mathrm{C} 1$, phloretin and phloridzin). However, $p$-coumaroylquinic acid was calculated as equivalents of $p$-coumaric acid. The results were expressed as milligrams per gram of dry extract $(\mathrm{mg} / \mathrm{g} \mathrm{DE})$. Three independent analyses were performed in each of the triplicate extracts obtained for each different methodology.

\subsection{Antioxidant Activity}

The antioxidant activity of BE apple extracts was evaluated through three different methods: ABTS, DPPH and ORAC, as described by Vilas-Boas et al. [15]. Ascorbic acid and Trolox was used as a standard for calibration curves, and the results were expressed as milligrams of ascorbic acid or Trolox equivalent per gram of dry extract (mg AAE/g DE or $\mathrm{mg} \mathrm{TE} / \mathrm{g} \mathrm{DE}$ ). Three independent analyses were performed in each of the triplicate extracts obtained for each different methodology.

\subsection{Statistical Analysis}

Data obtained for all the analyses were presented as the average \pm standard deviation of three independent extractions $(n=3)$, and analyzed through SPSS version 23, with one-way analysis of variance (ANOVA), after confirmed the normality of data distribution thought the Shapiro-Wilk test. Tukey's post hoc test was applied for comparison of means and the differences were considered significant at $p<0.05$. Furthermore, the principal component analysis (PCA) was performed, with Statgraphics Centurion XVII software, to the data set after normalization with factor analysis and Varimax method was used to produce orthogonal transformations to the reduced factors as to better identify the high and low correlations. 


\section{Conclusions}

This manuscript describes for the first time the bioactive potential that apples, one of the largest consumed fruit in the world, can have particularly non-compliant 'Bravo de Esmolfe' variety as a reliable source of polyphenols that could be extracted with sustainable technologies by the opposition to the traditional ones that uses large amounts of toxic solvents. The different extraction techniques (two green extractions (MAE and UAE) and two conventional extractions (CE and UAE)) were applied to compare the different technique to produce a natural antioxidant extract rich in polyphenols using non-compliant $\mathrm{BE}$ apples. Data indicate that both MAE and CET are good extraction methodologies for the development of a BE apple antioxidant extract rich in polyphenols comparatively to the other techniques tested. However, MAE is a better method as it is more sustainable than CET. Applying this sustainable extraction technique, it was possible to obtain an antioxidant extract with higher antioxidant activity and polyphenols, including hydroxycinnamic acids (4-caffeoylquinic acid and 5-caffeoylquinic), flavanols ((-)-epicatechin, $(+)$-catechin, and procyanidins) and chalcone (phoretin and phloridzin). Additionally, this study demonstrated the possibility of using non-compliant BE apple to produce new functional ingredients, such as antioxidant extracts. This might constitute a new and promising way for recovering high value-added compounds from the rejected fruit and which might be of use for human consumption or food industry purposes. Besides this, these circular economy approaches sensitize to the preservation of a traditional PGI variety and minimizing the losses feed, promoting the bioeconomic value of the fruit supply chain, integrating the circular and sustainable principles. To guarantee the food application of these BE apple extracts, future studies about their safeness, toxicity, stability and bioaccessibility will be necessary.

Author Contributions: Conceptualization, A.A.V.-B., A.O. and M.P.; investigation, methodology, validation A.A.V.-B., T.B.R., R.G.-G., C.N. and S.R.; formal analysis, A.A.V.-B. and A.O.; writing-original draft preparation, A.A.V.-B.; writing-review and editing, A.O.; supervision and project administration, M.P. and J.N. All authors have read and agreed to the published version of the manuscript.

Funding: This work was supported by Ministry of Agriculture and Rural Development and cofinanced by the European Agricultural Fund for Rural Development (EAFRD), through the partnership agreement Portugal PDR-2020, under the project Nature Bioactive Food: Desenvolvimento de produtos e ingredients alimentares bioativos através de recursos agrícolas endógenos portugueses para uma alimentação saudável (Ref. PDR2020-101-031531) and is a result of the Transfer Empreende project, supported by Norte Portugal Regional Operational Programme (NORTE 2020), under the PORTUGAL 2020 Partnership Agreement, through the European Regional Development Fund (ERDF).

Institutional Review Board Statement: Not applicable.

Informed Consent Statement: Not applicable.

Data Availability Statement: Not applicable.

Acknowledgments: The authors would like to thank the Nature Bioactive Food project (PDR2020-101031531), Transfer Empreende project (Norte-02-0651-FEDER-000081), supported by Norte Portugal Regional Operational Programme (NORTE 2020), and the scientific collaboration of Escola Superior de Biotecnologia of Universidade Católica Portuguesa through CBQF under the FCT project UIDB/50016/2020.

Conflicts of Interest: The authors declare no conflict of interest. 


\section{References}

1. Feliciano, R.P.; Antunes, C.; Ramos, A.; Serra, A.T.; Figueira, M.; Duarte, C.M.; de Carvalho, A.; Bronze, M.R. Characterization of traditional and exotic apple varieties from Portugal. Part 1 -Nutritional, phytochemical and sensory evaluation. J. Funct. Foods 2010, 2, 35-45. [CrossRef]

2. Serra, A.T.; Matias, A.A.; Frade, R.F.M.; Duarte, R.O.; Feliciano, R.P.; Bronze, M.R.; Figueira, M.E.; de Carvalho, A.; Duarte, C.M.M. Characterization of traditional and exotic apple varieties from Portugal. Part 2-Antioxidant and antiproliferative activities. J. Funct. Foods 2010, 2, 46-53. [CrossRef]

3. Pires, T.C.; Dias, M.I.; Barros, L.; Alves, M.J.; Oliveira, M.B.P.; Santos-Buelga, C.; Ferreira, I.C. Antioxidant and antimicrobial properties of dried Portuguese apple variety (Malus domestica Borkh. cv Bravo de Esmolfe). Food Chem. 2018, 240, 701-706. [CrossRef]

4. Serra, A.T.; Rocha, J.; Sepodes, B.; Matias, A.; Feliciano, R.P.; de Carvalho, A.; Bronze, M.R.; Duarte, C.M.; Figueira, M. Evaluation of cardiovascular protective effect of different apple varieties-Correlation of response with composition. Food Chem. 2012, 135, 2378-2386. [CrossRef]

5. European Commission. Commission Regulation (EC) No 85/2004 of 15 January 2004 laying down the marketing standard for apples. Off. J. Eur. Union 2004, 13, 3-18.

6. Guiné, R.; Andrade, S.; Correia, A.; Jordão, A.; Lopes, A.; Ferreira, D. Evaluation of textural properties in apples of regional varieties. Int. J. Food Prop. 2011, 14, 331-338. [CrossRef]

7. Reis, S.F.; Rocha, S.M.; Barros, A.S.; Delgadillo, I.; Coimbra, M.A. Establishment of the volatile profile of 'Bravo de Esmolfe' apple variety and identification of varietal markers. Food Chem. 2009, 113, 513-521. [CrossRef]

8. Campos, D.A.; Gómez-García, R.; Vilas-Boas, A.A.; Madureira, A.R.; Pintado, M. Management of fruit industrial by-productsOnly acknowledge a case study on circular economy approach. Molecules 2020, 25, 320. [CrossRef]

9. Radenkovs, V.; Püssa, T.; Juhnevica-Radenkova, K.; Kviesis, J.; Salar, F.J.; Moreno, D.A.; Drudze, I. Wild apple (Malus spp.) by-products as a source of phenolic compounds and vitamin C for food applications. Food Biosci. 2020, 38, 100744. [CrossRef]

10. Ofosu, F.K.; Daliri, E.B.-M.; Elahi, F.; Chelliah, R.; Lee, B.-H.; Oh, D.-H. New insights on the use of polyphenols as natural preservatives and their emerging safety concerns. Front. Sustain. Food Syst. 2020, 4, 223. [CrossRef]

11. Li, Y.; He, D.; Li, B.; Lund, M.N.; Xing, Y.; Wang, Y.; Li, F.; Cao, X.; Liu, Y.; Chen, X.; et al. Engineering polyphenols with biological functions via polyphenol-protein interactions as additives for functional foods. Trends Food Sci. Technol. 2021, 110, 470-482. [CrossRef]

12. Awasthi, M.K.; Ferreira, J.A.; Sirohi, R.; Sarsaiya, S.; Khoshnevisan, B.; Baladi, S.; Sindhu, R.; Binod, P.; Pandey, A.; Juneja, A.; et al. A critical review on the development stage of biorefinery systems towards the management of apple processing-derived waste. Renew. Sustain. Energy Rev. 2021, 143, 110972. [CrossRef]

13. Coelho, M.; Pereira, R.; Rodrigues, A.S.; Teixeira, J.A.; Pintado, M.M. Extraction of tomato by-products' bioactive compounds using ohmic technology. Food Bioprod. Process. 2019, 117, 329-339. [CrossRef]

14. Kerdudo, A.; Burger, P.; Merck, F.; Dingas, A.; Rolland, Y.; Michel, T.; Fernandez, X. Development of a natural ingredient-Natural preservative: A case study. Comptes Rendus Chim. 2016, 19, 1077-1089. [CrossRef]

15. Vilas-Boas, A.A.; Campos, D.A.; Nunes, C.; Ribeiro, S.; Nunes, J.; Oliveira, A.; Pintado, M. Polyphenol extraction by different techniques for valorisation of non-compliant portuguese sweet cherries towards a novel antioxidant extract. Sustainability 2020, 12, 5556. [CrossRef]

16. Zhang, Z.; Poojary, M.M.; Choudhary, A.; Rai, D.K.; Tiwari, B.K.B.K. Comparison of selected clean and green extraction technologies for biomolecules from apple pomace. Electrophoresis 2018, 39, 1934-1945. [CrossRef] [PubMed]

17. Đurović, S.; Nikolić, B.; Luković, N.; Jovanović, J.; Stefanović, A.; Šekuljica, N.; Mijin, D.; Knežević-Jugović, Z. The impact of high-power ultrasound and microwave on the phenolic acid profile and antioxidant activity of the extract from yellow soybean seeds. Ind. Crop. Prod. 2018, 122, 223-231. [CrossRef]

18. Perussello, C.A.; Zhang, Z.; Marzocchella, A.; Tiwari, B.K. Valorization of apple pomace by extraction of valuable compounds. Compr. Rev. Food Sci. Food Saf. 2017, 16, 776-796. [CrossRef]

19. Wijngaard, H.H.; Brunton, N. The optimisation of solid-liquid extraction of antioxidants from apple pomace by response surface methodology. J. Food Eng. 2010, 96, 134-140. [CrossRef]

20. Grigoras, C.G.; Destandau, E.; Fougère, L.; Elfakir, C. Evaluation of apple pomace extracts as a source of bioactive compounds. Ind. Crop. Prod. 2013, 49, 794-804. [CrossRef]

21. Mokrani, A.; Madani, K. Effect of solvent, time and temperature on the extraction of phenolic compounds and antioxidant capacity of peach (Prunus persica L.) fruit. Sep. Purif. Technol. 2016, 162, 68-76. [CrossRef]

22. Casazza, A.A.; Pettinato, M.; Perego, P. Polyphenols from apple skins: A study on microwave-assisted extraction optimization and exhausted solid characterization. Sep. Purif. Technol. 2020, 240, 116640. [CrossRef]

23. Blidi, S.; Bikaki, M.; Grigorakis, S.; Loupassaki, S.; Makris, D.P. A Comparative Evaluation of bio-solvents for the efficient extraction of polyphenolic phytochemicals: Apple waste peels as a case study. Waste Biomass Valorization 2015, 6, 1125-1133. [CrossRef]

24. Sánchez-Rabaneda, F.; Jáuregui, O.; Lamuela-Raventos, R.M.; Viladomat, F.; Bastida, J.; Codina, C. Qualitative analysis of phenolic compounds in apple pomace using liquid chromatography coupled to mass spectrometry in tandem mode. Rapid Commun. Mass Spectrom. 2004, 18, 553-563. [CrossRef] [PubMed] 
25. Bai, X.-L.; Yue, T.-L.; Yuan, Y.-H.; Zhang, H.-W. Optimization of microwave-assisted extraction of polyphenols from apple pomace using response surface methodology and HPLC analysis. J. Sep. Sci. 2010, 33, 3751-3758. [CrossRef]

26. Pingret, D.; Fabiano-Tixier, A.-S.; Le Bourvellec, C.; Renard, C.M.G.C.; Chemat, F. Lab and pilot-scale ultrasound-assisted water extraction of polyphenols from apple pomace. J. Food Eng. 2012, 111, 73-81. [CrossRef]

27. Wang, L.; Boussetta, N.; Lebovka, N.; Vorobiev, E. Effects of ultrasound treatment and concentration of ethanol on selectivity of phenolic extraction from apple pomace. Int. J. Food Sci. Technol. 2018, 53, 2104-2109. [CrossRef]

28. Mendoza-Wilson, A.M.; Castro-Arredondo, S.I.; Espinosa-Plascencia, A.; Robles-Burgueño, M.D.R.; Balandrán-Quintana, R.R.; Bermúdez-Almada, M.D.C. Chemical composition and antioxidant-prooxidant potential of a polyphenolic extract and a proanthocyanidin-rich fraction of apple skin. Heliyon 2016, 2, e00073. [CrossRef] [PubMed]

29. Górnaś, P.; Dwiecki, K.; Siger, A.; Tomaszewska-Gras, J.; Michalak, M.; Polewski, K. Contribution of phenolic acids isolated from green and roasted boiled-type coffee brews to total coffee antioxidant capacity. Eur. Food Res. Technol. 2016, 242, 641-653. [CrossRef]

30. Gu, C.; Howell, K.; Dunshea, F.R.; Suleria, H.A.R. LC-ESI-QTOF/MS characterisation of phenolic acids and flavonoids in polyphenol-rich fruits and vegetables and their potential antioxidant activities. Antioxidants 2019, 8, 405. [CrossRef]

31. Martini, S.; Conte-Junior, C.; Tagliazucchi, D. Phenolic compounds profile and antioxidant properties of six sweet cherry (Prunus avium) cultivars. Food Res. Int. 2017, 97, 15-26. [CrossRef]

32. Alberti, A.; Zielinski, A.A.F.; Zardo, D.M.; Demiate, I.M.; Nogueira, A.; Igarashi-Mafra, L. Optimisation of the extraction of phenolic compounds from apples using response surface methodology. Food Chem. 2014, 149, 151-158. [CrossRef]

33. Zielinska, D.; Laparra-Llopis, J.M.; Zielinski, H.; Szawara-Nowak, D.; Giménez-Bastida, J.A. Role of apple phytochemicals, phloretin and phloridzin, in modulating processes related to intestinal inflammation. Nutrients 2019, 11, 1173. [CrossRef] [PubMed]

34. Saleh, I.; Vinatoru, M.; Mason, T.J.; Abdel-Azim, N.; Aboutabl, E.; Hammouda, F. A possible general mechanism for ultrasoundassisted extraction (UAE) suggested from the results of UAE of chlorogenic acid from Cynara scolymus L. (artichoke) leaves. Ultrason. Sonochem. 2016, 31, 330-336. [CrossRef]

35. Pinelo, M.; Zornoza, B.; Meyer, A.S. Selective release of phenols from apple skin: Mass transfer kinetics during solvent and enzyme-assisted extraction. Sep. Purif. Technol. 2008, 63, 620-627. [CrossRef]

36. Tiwari, U.; Cummins, E. Factors influencing levels of phytochemicals in selected fruit and vegetables during pre- and post-harvest food processing operations. Food Res. Int. 2013, 50, 497-506. [CrossRef]

37. Kjellenberg, L.; Johansson, E.; Gustavsson, K.-E.; Olsson, M.E. Effects of harvesting date and storage on the amounts of pol-yacetylenes in carrots, Daucus carota. J. Agric. Food Chem. 2010, 58, 11703-11708. [CrossRef] [PubMed]

38. Schmitz-Eiberger, M.; Matthes, A. Effect of harvest maturity, duration of storage and shelf life of apples on the allergen Mal d 1, polyphenoloxidase activity and polyphenol content. Food Chem. 2011, 127, 1459-1464. [CrossRef]

39. Górnaś, P.; Mišina, I.; Olšteine, A.; Krasnova, I.; Pugajeva, I.; Lācis, G.; Siger, A.; Michalak, M.; Soliven, A.; Seglina, D. Phenolic compounds in different fruit parts of crab apple: Dihydrochalcones as promising quality markers of industrial apple pomace by-products. Ind. Crop. Prod. 2015, 74, 607-612. [CrossRef]

40. Zhang, Y.; Li, P.; Cheng, L. Developmental changes of carbohydrates, organic acids, amino acids, and phenolic compounds in 'Honeycrisp' apple flesh. Food Chem. 2010, 123, 1013-1018. [CrossRef]

41. Oh, M.-M.; Carey, E.; Rajashekar, C. Environmental stresses induce health-promoting phytochemicals in lettuce. Plant Physiol. Biochem. 2009, 47, 578-583. [CrossRef] [PubMed]

42. Berni, R.; Cantini, C.; Romi, M.; Hausman, J.-F.; Guerriero, G.; Cai, G. Agrobiotechnology goes wild: Ancient local varieties as sources of bioactives. Int. J. Mol. Sci. 2018, 19, 2248. [CrossRef] [PubMed]

43. Carocho, M.; Morales, P.; Ferreira, I.C. Antioxidants: Reviewing the chemistry, food applications, legislation and role as preservatives. Trends Food Sci. Technol. 2018, 71, 107-120. [CrossRef]

44. Dey, T.B.; Chakraborty, S.; Jain, K.K.; Sharma, A.; Kuhad, R.C. Antioxidant phenolics and their microbial production by submerged and solid state fermentation process: A review. Trends Food Sci. Technol. 2016, 53, 60-74. [CrossRef]

45. Faustino, A.M.; Veiga, M.; Sousa, P.; Costa, E.M.; Silva, S.; Pintado, M. Agro-food byproducts as a new source of natural food additives. Molecules 2019, 24, 1056. [CrossRef] [PubMed]

46. Alves-Silva, J.M.; dos Santos, S.M.D.; Pintado, M.M.; Pérez-Álvarez, J.A.; Fernández-López, J.; Viuda-Martos, M. Chemical composition and in vitro antimicrobial, antifungal and antioxidant properties of essential oils obtained from some herbs widely used in Portugal. Food Control. 2013, 32, 371-378. [CrossRef]

47. Kelebek, H.; Selli, S. Evaluation of chemical constituents and antioxidant activity of sweet cherry (Prunus avium L.) cultivars. Int. J. Food Sci. Technol. 2011, 46, 2530-2537. [CrossRef]

48. Kulczyński, B.; Gramza-Michałowska, A.; Królczyk, J.B. Optimization of extraction conditions for the antioxidant potential of different pumpkin varieties (Cucurbita maxima). Sustainability 2020, 12, 1305. [CrossRef]

49. Ribeiro, T.B.; Oliveira, A.L.; Costa, C.; Nunes, J.; Vicente, A.A.; Pintado, M. Total and sustainable valorisation of olive pomace using a fractionation approach. Appl. Sci. 2020, 10, 6785. [CrossRef]

50. Gómez-García, R.; Campos, D.A.; Oliveira, A.; Aguilar, C.N.; Madureira, A.R.; Pintado, M. A chemical valorisation of melon peels towards functional food ingredients: Bioactives profile and antioxidant properties. Food Chem. 2021, 335, 127579. [CrossRef] 
51. Dias, C.; Fonseca, A.; Amaro, A.L.; Vilas-Boas, A.A.; Oliveira, A.; Santos, S.A.O.; Silvestre, A.J.D.; Rocha, S.M.; Isidoro, N.; Pintado, M. Natural-based antioxidant extracts as potential mitigators of fruit browning. Antioxidants 2020, 9, 715. [CrossRef]

52. Ribeiro, T.B.; Oliveira, A.; Campos, D.; Nunes, J.; Vicente, A.A.; Pintado, M. Simulated digestion of an olive pomace water-soluble ingredient: Relationship between the bioaccessibility of compounds and their potential health benefits. Food Funct. 2020, 11, 2238-2254. [CrossRef]

53. Vilas-Boas, A.; Oliveira, A.; Jesus, D.; Rodrigues, C.; Figueira, C.; Gomes, A.; Pintado, M.M. Chlorogenic acids composition and the impact of in vitro gastrointestinal digestion on espresso coffee from single-dose capsule. Food Res. Int. 2020, 134, 109223. [CrossRef] [PubMed]

54. Soquetta, M.B.; Terra, L.D.M.; Bastos, C.P. Green technologies for the extraction of bioactive compounds in fruits and vegetables. CyTA J. Food 2018, 16, 400-412. [CrossRef]

55. Leadbeater, N. 9.10 Organic synthesis using microwave heating. In Comprehensive Organic Synthesis II, 2nd ed.; Elsevier: Amsterdam, The Netherlands, 2014; Volume 9, pp. 234-286.

56. Alexandre, E.; Silva, S.; Santos, S.A.; Silvestre, A.J.; Duarte, M.F.; Saraiva, J.A.; Pintado, M. Antimicrobial activity of pomegranate peel extracts performed by high pressure and enzymatic assisted extraction. Food Res. Int. 2019, 115, 167-176. [CrossRef] [PubMed] 